\title{
PERBAIKAN KUALITAS CITRA MAPS MENGGUNAKAN METODE CONTRAST LIMITED ADAPTIVE HISTOGRAM EQUALIZATION (CLAHE)
}

\author{
Dian Lestari Nasution
}

\author{
Program Studi Teknik Informatika STMIK Budi Darma, Medan, Indonesia \\ Email: dianlestar059@gmail.com
}

\begin{abstract}
Abstrak
Citra maps yang ada di google maps juga bisa di-screenshoot, pada saat pengambilan citra maps/peta kualitas gambar tidak maksimal, hal ini dikarenakan kemampuan dari komputer yang digunakan untuk mengambil citra tersebut tidak mendukung grafis yang tinggi. Citra maps ini dapat digunakan sebagai bahan untuk keperluan pekerjaan yang menggunakan citra seperti desain grafis yaitu percetakan.Kemampuan komputer yang tidak mendukung pengolahan grafis yang besar dalam mendapatkan citra yang baik tidak menjadi masalah utama dalam perbaikan citra. Karena citra yang tidak maksimal unsur warnanya dapat dimanipulasi dengan teknik pengolahan citra digital salah satu metode untuk memanipulasi unsure warna citra yaitu dengan metode CLAHE. Metode CLAHE diterapkan dan mengkalkulasi nilai piksel yang ada di masing-masing layer RGB. Dalam bidang desain grafis citra yang memiliki intensitas yang kurang dapat diperbaiki dengan peningkatan kontras. Peningkatan kontras citra dapat dilakukan dengan metode CLAHE.
\end{abstract}

Kata Kunci: Citra Maps, Kontras, CLAHE.

\begin{abstract}
Map images that are on Google Maps can also be screenshooted, when taking image maps / maps the image quality is not optimal, this is because the ability of the computer used to take the image does not support high graphics. This map image can be used as material for the purposes of work that uses images such as graphic design, namely printing.The ability of computers that do not support large graphics processing in getting a good image is not a major problem in image improvement. Because the image that is not maximized, its color elements can be manipulated with digital image processing techniques, one of the methods for manipulating elements of image colors is the CLAHE method. The CLAHE method is applied and calculates the pixel values that exist in each RGB layer. In the field of graphic design images that have less intensity can be improved by increasing contrast. Image contrast enhancement can be done by the CLAHE method.
\end{abstract}

Keywords: Maps Imagery, Contrast, CLAHE.

\section{PENDAHULUAN}

Citra peta (maps) digital sering kali digunakan untuk menelusuri, menjelajahi, dan menemukan jalan di seluruh dunia dan juga memberikan citra satelit, peta jalan, kondisi lalu lintas, dan perencanaan rute untuk bepergian dengan berjalan kaki, mobil, sepeda, atau angkutan umum. Citra maps yang ada di google maps juga bisa di-screenshoot, pada saat pengambilan citra maps/peta kualitas gambar tidak maksimal, hal ini dikarenakan kemampuan dari komputer yang digunakan untuk mengambil citra tersebut tidak mendukung grafis yang tinggi. Kenampakan hipsografi atau relief muka bumi, menggunakan warna dasar coklat, dari coklat muda sampai coklat tua, kenampakan hidrografi atau wilayah perairan (sungai, danau, laut), menggunakan warna dasar biru, dari biru muda (hampir putih) sampai biru tua (kehitaman) dan Kenampakan vegetasi (hutan, perkebunan), menggunakan warna dasar hijau. Warna hijau juga digunakan untuk menggambarkan wilayah dataran rendah.

\section{TEORITIS}

\subsection{Citra Digital}

Citra digital merupakan sebuah larik (array) yang berisi nilai-nilai real maupun komplek yang direpresentasikan dengan deretan bit tertentu. Citra yang disimpan dalam memori komputer hanyalah angka-angka yang menunjukkan besar intensitas pada masing-masing pixel tersebut. Sebuah citra digital dapat mewakili oleh sebuah matriks yang terdiri dari $\mathrm{M}$ kolom $\mathrm{N}$ baris, dimana perpotongan antara kolom dan baris disebut piksel (piksel = picture element) yaitu elemen terkecil dari sebuah citra. Piksel mempunyai dua parameter, yaitu koordinat dan intensitas atau warna. Nilai yang terdapat pada koordinat $(\mathrm{x}, \mathrm{y})$ adalah $\mathrm{f}(\mathrm{x}, \mathrm{y})$, yaitu besar intensitas atau warna dari piksel di titik itu [3].

\subsection{Peningkatan Kualitas Citra}

Peningkatan kualitas citra adalah suatu proses untuk mengubah sebuah citra menjadi citra baru sesuai dengan kebutuhan melalui berbagai cara. Cara-cara yang bisa dilakukan misalkan dengan fungsi transformasi, operasi matematis, pemfilteran, dan lain-lain. Tujuan utama dari peningkatan kualitas citra adalah untuk memproses citra 
sehingga citra yang dihasilkan lebih baik darpada citra aslinya untuk aplikasi tertentu. Peningkatan kualitas citra aslinya untuk aplikasi tertentu.

\subsection{CLAHE}

Contrast Limited Adaptive Histogram Equalization (CLAHE) merupakan versi perbaikan dari Adaptive Histogram Equalization (AHE) dimana masalah noise pada AHE dapat dikurangi dengan membatasi peningkatan kontras khususnya pada daerah yang homogen, yang dicirikan sebagai puncak yang tinggi pada histogram terkait dengan daerah kontekstual karena banyak piksel yang tergabung pada kisaran abu-abu yang sama [2].

Algoritma CLAHE dalam ruang warna YIQ dapat mencakup langkah-langkah berikut:

Langkah 1: Tiga komponen R, G dan B dalam gambar RGB dinormalisasi ke kisaran $[0,1]$ sebagai

$$
\begin{aligned}
& \mathrm{R} n(\mathrm{x}, \mathrm{y})=\frac{\mathrm{R}(\mathrm{x}, \mathrm{y})}{255} \\
& \mathrm{G} n(\mathrm{x}, \mathrm{y})=\frac{\mathrm{G}(\mathrm{x}, \mathrm{y})}{255} \\
& \mathrm{~B} n(\mathrm{x}, \mathrm{y})=\frac{\mathrm{B}(\mathrm{x}, \mathrm{y})}{255}
\end{aligned}
$$

Langkah 2 : Transformasi linear dari ruang warna RGB ke ruang warna YIQ

Langkah 3 : Komponen iluminansi (Yn) pada gambar YIQ ditingkatkan dengan Rayleigh CLAHE menjadidapatkan komponen pencahayaan yang lebih baik (Y'n).

Langkah 4 : Transformasi linear dari ruang warna YIQ ke belakang ke ruang warna RGB

Langkah 5 : Gambar RGB yang dinormalisasi mundur ke kisaran $[0,255]$

$$
\begin{aligned}
& \mathrm{R}^{\prime}=255 \text { X R'n } \\
& \mathrm{G}^{\prime}=255 \times \text { X'n } \\
& \mathrm{B}^{\prime}=255 \text { X B'n }
\end{aligned}
$$

Langkah 6 : Output akhir gambar RGB dapat dihitung sebagai

$$
\begin{aligned}
& \mathrm{R} 1=\frac{\mathrm{R}^{\prime}-\mathrm{R}^{\prime} \min }{\mathrm{R}{ }^{\prime} \max -\mathrm{R}^{\prime} \min } \\
& \mathrm{G} 1=\frac{\mathrm{G}^{\prime}-\mathrm{G}^{\prime} \min }{\mathrm{G}^{\prime} \mathrm{max}-\mathrm{R}^{\prime} \mathrm{min}} \\
& \mathrm{B} 1=\mathrm{B}^{\prime}-\mathrm{B}^{\prime} \mathrm{min} \\
& B^{\prime} \max -B^{\prime} \min
\end{aligned}
$$

\subsection{Maps/Peta}

Dalam pengertian sederhana, peta dapat diartikan sebagai sebuah (dokumen resmi mengenai) bentuk sajian (presentasi) atau gambaran (miniature) mengenai unsur-unsur spasial (features) yang (pada umumnya) terdapat di permukaan bumi pada sebuah (media) bidang datar (atau yang telah "didatarkan"). Pembuatan dokumen resmi ini, sebagai hasil perekaman "perjalanan" yang panjang (survey), bertujuan untuk mempublikasikan dan mengkomunikasikan data, informasi, dan pengetahuan mengenai unsur-unsur spasial yang telah dikumpulkan, dikembangkan, dan kemudian dikompilasi oleh (tim/pihak) pembuatnya [6].

\section{ANALISA DAN PEMBAHASAN}

Perbaikan kualitas citra maps dilakukan dengan metode Contrass Limited Adaptive Histogram Equalization (CLAHE). Metode CLAHE melakukan peningkatan penyebaran kontras dengan menggunakan transformasi RGB ke YIQ dan YIQ ke RGB dengan melakukan normalisasi maksimum dan minimum warna tersebut. Tujuan dalam kegiatan analisa ini adalah melakukan peningkatan kecerahan citra peta yang diambil dari aplikasi peta seperti google maps. Pada saat pengambilan citra peta kualitas gambar tidak maksimal, hal ini dikarenakan kemampuan dari komputer yang digunakan untuk mengambil citra tersebut tidak mendukung grafis yang tinggi atau spesifikasi utama dan pengaturan dari komputer yang memadai untuk mengolah citra yang ditampilkan aplikasi google maps.

\subsection{Penerapan Metode CLAHE}

Metode CLAHE digunakan untuk meningkatkan kontras citra dengan mengubah nilai intensitas dalam citra CLAHE beroperasi pada daerah yang kecil yang disebut sebagai tile, CLAHE menerapkan interpolasi bilinier untuk mengeliminasi adanya region boundaries oleh karena itu daerah-daerah kecil yang bertetangga terlihat lebih halus atau tidak terlihat batasnya. 
Berikut telah disiapkan citra maps yang mengalami gangguan seperti masalah kecerahan dan noise dengan dimensi 521 x 249 dan telah ditransformasikan menjadi 20 × 20 dengan format JPG. Berikut tampilan yang dijadikan sampel pengujian.

Adapun Scrift matlab adalah sebagai berikut :

dian= imread ('D:Icitra_maps.jpg') ;

dian $=\operatorname{imcrop}(\operatorname{dian},[1,1,19,19])$;

$\mathrm{r}=\operatorname{dian}(:,:, 1)$;

$\mathrm{g}=\operatorname{dian}(:,:, 2)$;

$\mathrm{b}=\operatorname{dian}(:,:, 3)$;

figure, imshow (dian) ;

Nilai piksel 20 × 20 diambil dari sudut bagian kiri atas seperti yang digambarkan dibawah ini :
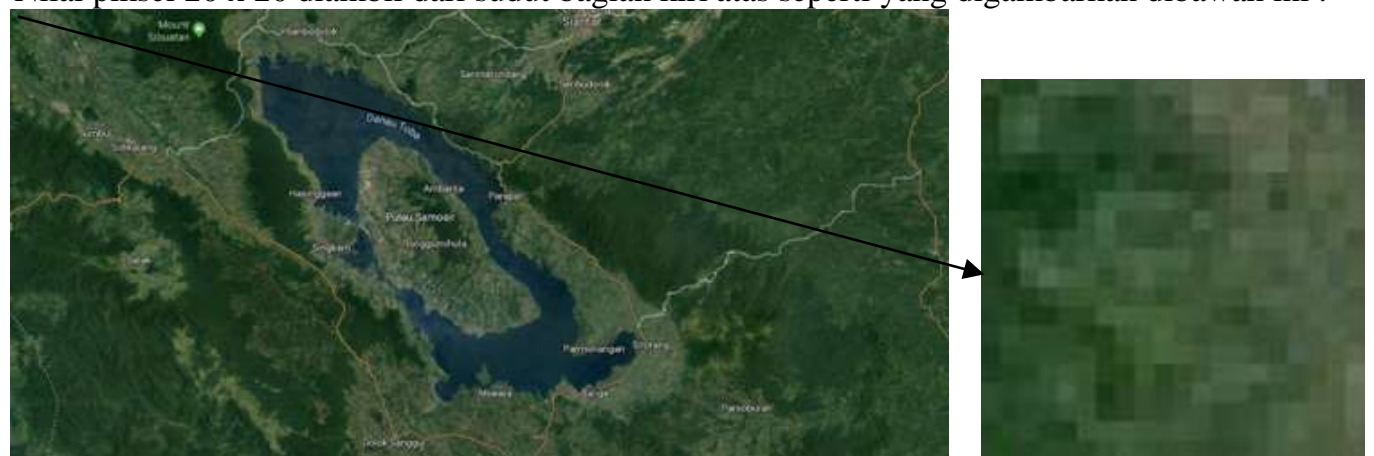

Gambar 1. Citra_maps.jpg

Gambar 2. Citra Sampel

Proses perbaikan kualitas citra bekerja pada pixel RGB yang ada didalam citra, untuk mendapatkan nilai pixel pada citra tidak bisa dilakukan secara manual dan harus menggunakan software khusus, pada penelitian ini penulis menggunakan Matlab R2014a, berikut adalah nilai matrik untuk Pixel R:

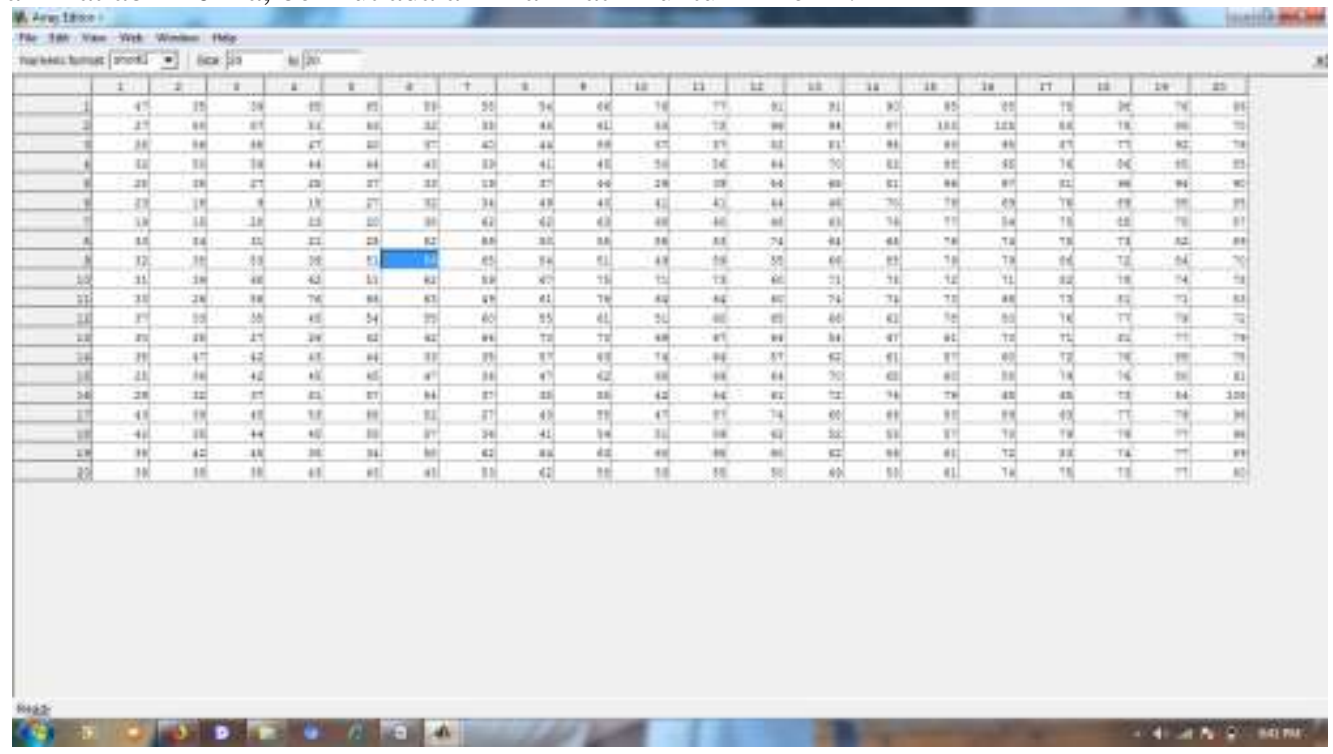

Gambar 3. Matrik pixsel warna Red 20x20

Langkah 1: Tiga komponen R, G dan B dalam gambar RGB dinormalisasi ke kisaran [0, 1] sebagai

$$
\begin{aligned}
& R n(x, y)=\frac{R(x, y)}{255} \\
& G n(x, y)=\frac{G(x, y)}{255} \\
& B n(x, y)=\frac{B(x, y)}{255}
\end{aligned}
$$

Pada gambar 3.3 bisa dilihat terdapat nilai-nilai matriks dalam baris dan kolom yang ada didalam gambar tersebut. Adapun cara untuk menghitung nilai matriks yang akan dinormalisasi adalah sebagai berikut :

Contoh: $\operatorname{Rn}(0,0)=\mathrm{R} 47 \frac{=0,18}{255}$

$$
\operatorname{Rn}(0,1)=\mathrm{R} 35=0,14
$$




\begin{tabular}{|c|c|c|c|c|c|c|c|c|c|c|c|c|c|c|c|c|c|c|c|c|}
\hline \multicolumn{21}{|c|}{$\begin{array}{l}\operatorname{sn}(0,2)=R \frac{39=0}{255}, 15 \\
\operatorname{Rn}(0,3)=R \frac{65=0}{255}, 25\end{array}$} \\
\hline Step 1 & \multicolumn{20}{|c|}{ Normalisasi } \\
\hline$(x, y)$ & 0 & 1 & 2 & 3 & 4 & 5 & 6 & 7 & 8 & 9 & 10 & 11 & 12 & 13 & 14 & 15 & 16 & 17 & 18 & 19 \\
\hline 0 & \begin{tabular}{l|l}
0.18 \\
\end{tabular} & 0.14 & 0.15 & 0.25 & 0.25 & 0.23 & 0.23 & 0.21 & \begin{tabular}{|l|}
0.26 \\
\end{tabular} & \begin{tabular}{|l|l|}
0.30 \\
\end{tabular} & \begin{tabular}{|l|}
0.30 \\
\end{tabular} & \begin{tabular}{|l|}
0.36 \\
\end{tabular} & 0.36 & \begin{tabular}{|l|}
0.35 \\
\end{tabular} & 0.37 & \begin{tabular}{|l|}
0.33 \\
\end{tabular} & \begin{tabular}{|l|}
0.31 \\
\end{tabular} & \begin{tabular}{|l|}
0.38 \\
\end{tabular} & 0.30 & 0.26 \\
\hline 1 & \begin{tabular}{l|l|} 
& \\
\end{tabular} & 0.20 & $\begin{array}{ll}0.22 \\
\end{array}$ & 0.20 & 0.17 & 0.13 & \begin{tabular}{|l|}
0.14 \\
\end{tabular} & \begin{tabular}{|l|}
0.18 \\
\end{tabular} & \begin{tabular}{|l|}
0.24 \\
\end{tabular} & 0.21 & \begin{tabular}{|l|l|}
0.28 \\
\end{tabular} & \begin{tabular}{l|l|} 
& \\
\end{tabular} & \begin{tabular}{|l|l|}
0.37 \\
\end{tabular} & \begin{tabular}{|l|}
0.34 \\
\end{tabular} & 0.40 & \begin{tabular}{|l|}
0.41 \\
\end{tabular} & \begin{tabular}{|l|}
0.31 \\
\end{tabular} & 0.31 & \begin{tabular}{|l|l|}
0.33 \\
\end{tabular} & 0.27 \\
\hline 2 & 0.11 & 0.22 & 0.27 & 0.18 & 0.16 & 0.15 & \begin{tabular}{|l|}
0.16 \\
\end{tabular} & 0.17 & 0.23 & 0.22 & \begin{tabular}{|l|}
0.22 \\
\end{tabular} & 0.32 & 0.32 & 0.37 & 0.36 & 0.37 & \begin{tabular}{|l|}
0.34 \\
\end{tabular} & 0.30 & 0.36 & 0.30 \\
\hline 3 & \begin{tabular}{l|l}
0.13 \\
\end{tabular} & 0.20 & 0.23 & 0.17 & 0.17 & 0.17 & 0.15 & 0.16 & 0.18 & 0.20 & \begin{tabular}{|l|l|}
0.22 \\
\end{tabular} & 0.25 & 0.27 & 0.32 & 0.35 & 0.37 & \begin{tabular}{|l|}
0.30 \\
\end{tabular} & 0.34 & 0.33 & 0.33 \\
\hline 4 & \begin{tabular}{l|l}
0.11 \\
\end{tabular} & 0.14 & 0.11 & 0.10 & 0.15 & 0.13 & \begin{tabular}{|l|}
0.07 \\
\end{tabular} & 0.15 & 0.17 & 0.11 & \begin{tabular}{|l|}
0.15 \\
\end{tabular} & 0.21 & 0.25 & 0.32 & 0.38 & 0.38 & \begin{tabular}{|l|}
0.32 \\
\end{tabular} & 0.38 & 0.37 & 0.35 \\
\hline 5 & \begin{tabular}{l|l}
0.09 \\
\end{tabular} & 0.06 & 0.04 & 0.07 & 0.11 & 0.13 & \begin{tabular}{|l|l|}
0.13 \\
\end{tabular} & 0.19 & 0.16 & 0.16 & \begin{tabular}{|l|l|}
0.16 \\
\end{tabular} & 0.17 & 0.18 & 0.27 & 0.31 & 0.27 & \begin{tabular}{|l|}
0.30 \\
\end{tabular} & 0.35 & 0.33 & 0.33 \\
\hline 6 & 0.07 & 0.06 & 0.08 & 0.09 & 0.08 & 0.15 & \begin{tabular}{|l|}
0.24 \\
\end{tabular} & 0.24 & 0.25 & 0.27 & \begin{tabular}{|l|l|}
0.24 \\
\end{tabular} & 0.19 & 0.25 & 0.30 & 0.30 & 0.21 & \begin{tabular}{|l|}
0.29 \\
\end{tabular} & 0.33 & 0.29 & \begin{tabular}{|l|}
0.34 \\
\end{tabular} \\
\hline 7 & \begin{tabular}{l|l|l}
0.13 & \\
\end{tabular} & 0.13 & 0.12 & 0.08 & 0.11 & 0.20 & \begin{tabular}{|l|}
0.27 \\
\end{tabular} & 0.20 & \begin{tabular}{|l|}
0.22 \\
\end{tabular} & 0.22 & \begin{tabular}{|l|}
0.21 \\
\end{tabular} & 0.29 & 0.25 & \begin{tabular}{|l|}
0.27 \\
\end{tabular} & 0.30 & 0.29 & \begin{tabular}{|l|}
0.30 \\
\end{tabular} & 0.29 & 0.32 & 0.35 \\
\hline 8 & \begin{tabular}{l|l|}
0.13 & \\
\end{tabular} & 0.15 & 0.21 & 0.15 & 0.20 & 0.22 & \begin{tabular}{|l|}
0.25 \\
\end{tabular} & 0.21 & \begin{tabular}{|l|}
0.20 \\
\end{tabular} & 0.19 & \begin{tabular}{|l|l|}
0.23 \\
\end{tabular} & \begin{tabular}{l|l|} 
& \\
\end{tabular} & $\begin{array}{ll}0.26 \\
\end{array}$ & \begin{tabular}{|l|}
0.33 \\
\end{tabular} & 0.31 & \begin{tabular}{|l|}
0.31 \\
\end{tabular} & \begin{tabular}{|l|}
0.34 \\
\end{tabular} & 0.28 & 0.33 & 0.27 \\
\hline 9 & 0.12 & 0.15 & 0.27 & 0.24 & 0.20 & 0.24 & 0.23 & 0.26 & 0.29 & 0.28 & \begin{tabular}{|l|}
0.29 \\
\end{tabular} & 0.24 & 0.28 & 0.31 & 0.28 & 0.28 & \begin{tabular}{|l|}
0.32 \\
\end{tabular} & 0.31 & 0.29 & 0.31 \\
\hline 10 & 0.13 & 0.10 & 0.22 & 0.30 & 0.26 & 0.25 & 0.19 & 0.24 & \begin{tabular}{|l|}
0.30 \\
\end{tabular} & 0.25 & 0.25 & 0.24 & 0.29 & \begin{tabular}{|l|l|}
0.29 \\
\end{tabular} & 0.29 & 0.26 & 0.29 & 0.32 & 0.28 & 0.33 \\
\hline 11 & 0.15 & 0.13 & 0.14 & 0.18 & 0.21 & 0.22 & \begin{tabular}{|l|}
0.24 \\
\end{tabular} & 0.22 & \begin{tabular}{|l|}
0.24 \\
\end{tabular} & 0.20 & \begin{tabular}{|l|l|}
0.24 \\
\end{tabular} & 0.25 & 0.26 & \begin{tabular}{|l|}
0.24 \\
\end{tabular} & 0.31 & \begin{tabular}{|l|}
0.31 \\
\end{tabular} & 0.30 & 0.30 & 0.31 & 0.28 \\
\hline 12 & 0.12 & 0.15 & 0.11 & 0.10 & 0.16 & 0.16 & 0.25 & 0.27 & \begin{tabular}{|l|}
0.27 \\
\end{tabular} & \begin{tabular}{|l|}
0.27 \\
\end{tabular} & \begin{tabular}{|l|}
0.26 \\
\end{tabular} & 0.25 & 0.21 & \begin{tabular}{|l|l|}
0.18 \\
\end{tabular} & 0.24 & \begin{tabular}{|l|}
0.27 \\
\end{tabular} & \begin{tabular}{|l|} 
\\
\end{tabular} & 0.32 & \begin{tabular}{|l|}
0.30 \\
\end{tabular} & 0.31 \\
\hline 13 & 0.14 & 0.18 & 0.16 & 0.17 & 0.17 & 0.13 & \begin{tabular}{|l|}
0.14 \\
\end{tabular} & 0.22 & \begin{tabular}{|l|}
0.25 \\
\end{tabular} & \begin{tabular}{|l|}
0.29 \\
\end{tabular} & \begin{tabular}{|l|l|}
0.25 \\
\end{tabular} & 0.22 & 0.24 & \begin{tabular}{|l|}
0.24 \\
\end{tabular} & 0.20 & \begin{tabular}{|l|l|}
0.24 \\
\end{tabular} & \begin{tabular}{|l|l|}
0.28 \\
\end{tabular} & 0.30 & \begin{tabular}{|l|}
0.33 \\
\end{tabular} & 0.31 \\
\hline 14 & 0.10 & 0.15 & 0.16 & 0.18 & 0.18 & \begin{tabular}{|l|l|}
0.18 \\
\end{tabular} & \begin{tabular}{|l|}
0.14 \\
\end{tabular} & 0.18 & \begin{tabular}{|l|l|}
0.24 \\
\end{tabular} & \begin{tabular}{|l|}
0.27 \\
\end{tabular} & \begin{tabular}{|l|}
0.27 \\
\end{tabular} & 0.25 & 0.27 & \begin{tabular}{|l|l|}
0.27 \\
\end{tabular} & 0.24 & \begin{tabular}{|l|l|} 
\\
\end{tabular} & \begin{tabular}{|l|}
0.31 \\
\end{tabular} & \begin{tabular}{|l|}
0.30 \\
\end{tabular} & \begin{tabular}{|l|l|} 
\\
\end{tabular} & 0.36 \\
\hline 15 & 0.11 & 0.13 & 0.15 & 0.20 & 0.22 & 0.21 & \begin{tabular}{|l|l|}
0.15 \\
\end{tabular} & 0.15 & \begin{tabular}{|l|}
0.23 \\
\end{tabular} & \begin{tabular}{|l|l|}
0.16 \\
\end{tabular} & \begin{tabular}{|l|}
0.21 \\
\end{tabular} & 0.24 & 0.28 & \begin{tabular}{|l|}
0.30 \\
\end{tabular} & 0.31 & 0.25 & \begin{tabular}{|l|l|}
0.25 \\
\end{tabular} & \begin{tabular}{|l|}
0.29 \\
\end{tabular} & \begin{tabular}{|l|}
0.33 \\
\end{tabular} & 0.41 \\
\hline 16 & \begin{tabular}{|l|l|}
0.17 \\
\end{tabular} & 0.15 & 0.18 & 0.21 & 0.27 & 0.20 & \begin{tabular}{|l|}
0.11 \\
\end{tabular} & 0.17 & 0.22 & \begin{tabular}{|l|l|}
0.18 \\
\end{tabular} & \begin{tabular}{|l|}
0.22 \\
\end{tabular} & \begin{tabular}{|l|l|}
0.29 \\
\end{tabular} & 0.27 & 0.26 & 0.21 & 23 & \begin{tabular}{|l|} 
\\
\end{tabular} & \begin{tabular}{|l|}
0.30 \\
\end{tabular} & 31 & 38 \\
\hline 17 & \begin{tabular}{l|l}
0.16 \\
\end{tabular} & 0.14 & 0.17 & 0.18 & 0.22 & 0.22 & \begin{tabular}{|l|}
0.14 \\
\end{tabular} & 0.16 & 0.21 & 0.20 & 23 & 0.24 & 0.20 & 0.22 & 0.22 & 0.27 & \begin{tabular}{|l|}
0.31 \\
\end{tabular} & \begin{tabular}{|l|l|}
0.31 \\
\end{tabular} & 0.30 & 38 \\
\hline 18 & \begin{tabular}{l|l|l|l|}
0.14 \\
\end{tabular} & 0.16 & \begin{tabular}{|l|}
0.18 \\
\end{tabular} & 0.14 & 0.13 & 0.23 & \begin{tabular}{|l|}
0.24 \\
\end{tabular} & 0.25 & 0.25 & \begin{tabular}{|l|}
0.24 \\
\end{tabular} & \begin{tabular}{|l|}
0.25 \\
\end{tabular} & \begin{tabular}{l|l}
0.24 \\
\end{tabular} & 0.20 & 0.22 & 0.24 & 0.28 & \begin{tabular}{|l|}
0.33 \\
\end{tabular} & \begin{tabular}{|l|}
0.29 \\
\end{tabular} & \begin{tabular}{|l|}
0.30 \\
\end{tabular} & 0.35 \\
\hline 19 & \begin{tabular}{l|l}
0.15 \\
\end{tabular} & 0.15 & 0.15 & 0.17 & 0.17 & 0.17 & \begin{tabular}{|l|}
0.21 \\
\end{tabular} & 0.24 & 0.23 & 0.21 & \begin{tabular}{|l|}
0.22 \\
\end{tabular} & \begin{tabular}{l|l}
0.20 \\
\end{tabular} & 0.19 & 0.21 & 0.24 & 0.29 & \begin{tabular}{|l|}
0.29 \\
\end{tabular} & 0.29 & 0.30 & 0.31 \\
\hline
\end{tabular}

Gambar 4. Tabel Normalisasi warna RED

Langkah 2: Transformasi linear dari ruang warna RGB ke ruang warna YIQ

Pada gambar 5. di bawah ini akan ditransformasi yaitu dengan mengalikan kolom (nilai normalisasi) dan baris (nilai matriks), setelah mendapatkan hasil dari nilai kolom dikali baris maka nilai tersebut dijadikan nilai YIQ. Adapun cara menghitung transformasi linier adalah sebagai berikut :

$(0,0)=(0.18 * 47)+(0.11 * 35)+(0.11 * 39)+(0.13 * 65)+(0.11 * 65)+(0.09 * 59)+(0.07 * 58)+(0.13 * 54)+(0.13 * 66)+(0.12 * 76)+$ $(0.13 * 77)+(0.15 * 91)+(0.12 * 91)+(0.14 * 90)+(0.10 * 95)+(0.11 * 85)+(0.17 * 78)+(0.16 * 98)+(0.14 * 76)+(0.15 * 66)=181$

\begin{tabular}{|c|c|c|c|c|c|c|c|c|c|c|c|c|c|c|c|c|c|c|c|c|}
\hline$e p 2$ & \multicolumn{20}{|c|}{$\mathrm{YIQ}$} \\
\hline$(x, y)$ & 0 & 1 & 2 & 3 & 4 & 5 & 6 & 7 & 8 & 9 & 10 & 11 & 12 & 13 & 14 & 15 & 16 & 17 & 18 & 19 \\
\hline 0 & 181 & 202 & 230 & 238 & 258 & 267 & 259 & 290 & 329 & \begin{tabular}{|l|}
314 \\
\end{tabular} & 333 & 347 & 359 & 383 & 397 & 403 & 421 & 439 & 445 & 467 \\
\hline 1 & 170 & 195 & 221 & 227 & 246 & 251 & 242 & 271 & 311 & 294 & 315 & 331 & 340 & 358 & 371 & 378 & \begin{tabular}{|l|l|}
394 \\
\end{tabular} & 407 & 418 & 439 \\
\hline 2 & 169 & 195 & 221 & 224 & 241 & 246 & 238 & 269 & 307 & 292 & 311 & 328 & 337 & 355 & 367 & 376 & 391 & 403 & 415 & 433 \\
\hline 3 & 159 & 182 & 205 & 210 & 226 & 231 & 222 & 251 & 288 & 273 & 292 & 308 & 315 & \begin{tabular}{|l|l|}
334 \\
\end{tabular} & 346 & 353 & 368 & 380 & 390 & 410 \\
\hline 4 & 145 & 163 & 180 & 188 & 205 & 210 & 198 & 225 & 257 & 244 & 262 & 274 & 277 & 291 & 300 & 11 & \begin{tabular}{|l|}
328 \\
\end{tabular} & 339 & 349 & 372 \\
\hline 5 & 128 & 139 & 156 & 164 & 179 & 187 & 179 & 201 & 227 & 216 & 230 & 237 & 240 & 254 & 260 & 268 & 288 & 298 & 304 & 328 \\
\hline 6 & 141 & 154 & 178 & 183 & 197 & 210 & 207 & 230 & 257 & 247 & 259 & 263 & 270 & 288 & 294 & 300 & 325 & 334 & 340 & 363 \\
\hline 7 & 149 & 163 & 185 & 193 & 209 & 220 & 218 & 242 & 271 & 259 & 274 & 283 & 291 & 309 & 320 & 324 & 344 & 356 & 363 & 383 \\
\hline 8 & 156 & 176 & 198 & 203 & 219 & 228 & 222 & 251 & 284 & 271 & 287 & 302 & 311 & 332 & 343 & 346 & 364 & 379 & 387 & 407 \\
\hline 9 & 168 & 191 & 220 & 222 & 238 & 248 & 244 & 272 & 306 & 292 & 310 & 326 & 337 & 363 & 375 & 380 & 396 & 409 & 418 & 436 \\
\hline 10 & 166 & 182 & 207 & 218 & 234 & 244 & 238 & 266 & 299 & 287 & 304 & 318 & 331 & 356 & 370 & 371 & 386 & 406 & 406 & 424 \\
\hline 11 & 154 & \begin{tabular}{|l|}
170 \\
\end{tabular} & 193 & 200 & 217 & 227 & 221 & 246 & 278 & 264 & 281 & 295 & 304 & 326 & 338 & 342 & 358 & 373 & \begin{tabular}{|l|}
379 \\
\end{tabular} & 399 \\
\hline 12 & 148 & 161 & 188 & 193 & 208 & 221 & 218 & 239 & 269 & 254 & 271 & 282 & 291 & 312 & 323 & 326 & \begin{tabular}{|l|l|}
344 \\
\end{tabular} & 354 & 360 & 381 \\
\hline 13 & 149 & 167 & 194 & 196 & 209 & 219 & 213 & 237 & 267 & 253 & 271 & 284 & 292 & 310 & 322 & 330 & \begin{tabular}{|l}
342 \\
\end{tabular} & 352 & 359 & 375 \\
\hline 14 & 152 & 170 & 196 & 199 & 214 & 222 & 217 & 243 & 273 & 259 & 276 & 288 & 296 & 316 & 327 & 336 & 350 & 361 & 369 & 386 \\
\hline 15 & 153 & 166 & 186 & 200 & 215 & 221 & 216 & 241 & 273 & 264 & 279 & 293 & 302 & 321 & 333 & 334 & 349 & 368 & 368 & 384 \\
\hline 16 & 152 & 170 & 191 & 195 & 212 & 218 & 213 & 239 & 268 & 254 & 272 & 288 & 294 & 315 & 331 & 340 & 349 & 363 & 369 & 382 \\
\hline 17 & 150 & 165 & 188 & 195 & 210 & 217 & 208 & 234 & 264 & 249 & 267 & 283 & 290 & \begin{tabular}{|l|l|}
311 \\
\end{tabular} & 324 & 331 & 342 & 356 & 362 & 379 \\
\hline 18 & 153 & 168 & 194 & 200 & 215 & 225 & 222 & 245 & 276 & 262 & 279 & 293 & 302 & 323 & 334 & 338 & \begin{tabular}{|l|}
354 \\
\end{tabular} & 366 & 373 & 393 \\
\hline 19 & 148 & \begin{tabular}{|l|}
161 \\
\end{tabular} & 185 & 193 & 207 & 215 & 209 & 230 & 260 & 249 & 266 & 282 & 289 & \begin{tabular}{|l|}
308 \\
\end{tabular} & 320 & 323 & 335 & 349 & 351 & 366 \\
\hline
\end{tabular}

Gambar 5. Tabel Hasil Trasformasi Linier

Langkah 3: Komponen iluminansi (model pencahayaan) (Yn) pada gambar YIQ ditingkatkan dengan Rayleigh CLAHE menjadi dapatkan komponen pencahayaan yang lebih baik (Y'n).

Pada gambar6. dibawah ini hanya menuliskan hasil yang didapatkan dari nilai YIQ, tetapi nilainya dibalikkan yaitu yamg kolom ditullis menjadi baris atau yang baris ditulis menjadi kolom. 


\begin{tabular}{|c|c|c|c|c|c|c|c|c|c|c|c|c|c|c|c|c|c|c|c|c|}
\hline \multirow{2}{*}{$\begin{array}{l}\text { Step } 3 \\
(x, y)\end{array}$} & \multicolumn{20}{|c|}{$T 11$} \\
\hline & 0 & 1 & 2 & 3 & 4 & 5 & 6 & 7 & 8 & 9 & 10 & 11 & 12 & 13 & 14 & 15 & 16 & 17 & 18 & 19 \\
\hline 0 & 181 & 170 & 169 & 159 & 145 & 128 & 141 & 149 & 156 & 168 & 166 & 154 & 148 & 149 & 152 & 153 & 152 & 150 & 153 & 148 \\
\hline 1 & 202 & 195 & 195 & 182 & 163 & 139 & 154 & 163 & 176 & 191 & 182 & 170 & 161 & 167 & 170 & 166 & 170 & 165 & 168 & 161 \\
\hline 2 & 230 & 21 & 221 & 205 & 180 & 156 & 178 & 185 & 198 & 220 & 207 & 193 & 188 & 194 & 196 & 186 & 191 & 188 & 194 & 185 \\
\hline 3 & 238 & 227 & 224 & 210 & 188 & 164 & 183 & 193 & 203 & 222 & 218 & 200 & 193 & 196 & 199 & 200 & 195 & 195 & 200 & 193 \\
\hline 4 & 258 & 246 & 241 & 226 & 205 & 179 & 197 & 209 & 219 & 238 & 234 & 217 & 208 & 209 & 214 & 215 & 212 & 210 & 215 & 207 \\
\hline 5 & 267 & 251 & 246 & 231 & 210 & 187 & 210 & 220 & 228 & 248 & 244 & 227 & 221 & 219 & 222 & 221 & 218 & 217 & 225 & 215 \\
\hline 6 & 259 & 42 & 238 & 222 & 198 & 179 & 207 & 218 & 222 & 244 & 238 & 221 & 218 & 213 & 217 & 216 & 213 & 208 & 222 & 209 \\
\hline 7 & 290 & 271 & 269 & 251 & 225 & 201 & 230 & 242 & 251 & 272 & 266 & 246 & 239 & 237 & 243 & 241 & 239 & 234 & 245 & 230 \\
\hline 8 & 329 & 311 & 307 & 288 & 257 & 227 & 257 & 271 & 284 & 306 & 299 & 278 & 269 & 267 & 273 & 273 & 268 & 264 & 276 & 260 \\
\hline 9 & 314 & 294 & 292 & 273 & 244 & 216 & 247 & 259 & 271 & 292 & 287 & 264 & 254 & 253 & 259 & 264 & 254 & 249 & 262 & 249 \\
\hline 10 & 333 & 315 & 311 & 292 & 262 & 230 & 259 & 274 & 287 & 310 & 304 & 281 & 271 & 271 & 276 & 279 & 272 & 267 & 279 & 266 \\
\hline 11 & 347 & 331 & 328 & 308 & 274 & 237 & 263 & 283 & 302 & 326 & 318 & 295 & 282 & 284 & 288 & 293 & 288 & 283 & 293 & 282 \\
\hline 12 & 359 & 340 & 337 & 315 & 277 & 240 & 270 & 291 & 311 & 337 & 331 & 304 & 291 & 292 & 296 & 302 & 294 & 290 & 302 & 289 \\
\hline 13 & 383 & 358 & 355 & 334 & 291 & 254 & 288 & 309 & 332 & 363 & 356 & 326 & 312 & 310 & 316 & 321 & 315 & 311 & 323 & 308 \\
\hline 14 & 397 & 371 & 367 & 346 & 300 & 260 & 294 & 320 & 343 & 375 & 370 & 338 & 323 & 322 & 327 & 333 & 331 & 324 & 334 & 320 \\
\hline 15 & 403 & 378 & 376 & 353 & 311 & 268 & 300 & 324 & 346 & 380 & 371 & 342 & 326 & 330 & 336 & 334 & 340 & 331 & 338 & 323 \\
\hline 16 & 421 & 394 & 391 & 368 & 328 & 288 & 325 & 344 & 364 & 396 & 386 & 358 & 344 & 342 & 350 & 349 & 349 & 342 & 354 & 335 \\
\hline 17 & 439 & 407 & 403 & 380 & 339 & 298 & 334 & 356 & 379 & 409 & 406 & 373 & 354 & 352 & 361 & 368 & 363 & 356 & 366 & 349 \\
\hline 18 & 445 & 418 & 415 & 390 & 349 & 304 & 340 & 363 & 387 & 418 & 406 & 379 & 360 & 359 & 369 & 368 & 369 & 362 & 373 & 351 \\
\hline 19 & 467 & 439 & 433 & 410 & 372 & 328 & 363 & 383 & 407 & 436 & 424 & 399 & 381 & 375 & 386 & 384 & 382 & 379 & 393 & 366 \\
\hline
\end{tabular}

Gambar 6. Komponen iluminansi berwarna Red

Langkah 4: Transformasi linear dari ruang warna YIQ ke belakang ke ruang warna RGB

Pada ga,bar 7 di bawah ini akan ditransformasikan lagi yaitu mengalikan kolom (nilai Y'n) dan baris (nilai YIQ), dimulai dari kolom 0 nilai Y'n dan baris 0 nilai YIQ, untuk lebih jelasnya bisa di lihat pada pengerjaan dibawah ini. $(0,0)=(181 * 181)+(202 * 202)+(230 * 230)+(238 * 238)+(258 * 258)+(267 * 267)+(259 * 259)+(290 * 290)+(329 * 329)+(314 *$ $314)+(333 * 333)+(347 * 347)+(359 * 359)+(383 * 383)+(397 * 397)+(403 * 403)+(421 * 421)+(439 * 439)+(445 * 445)+(467 *$ $467)=2292303$

\begin{tabular}{|c|c|c|c|c|c|c|c|c|c|c|c|c|c|c|c|c|c|c|c|c|}
\hline & & & & & & & & & & & & & & & & & & & & \\
\hline & & 55712 & 34472 & 2005227 & 85960 & 563820 & 1756751 & 1869399 & 80476 & 2149574 & 2101773 & 1945599 & 1865020 & 1861358 & 1901409 & 1909175 & 1891257 & & & \\
\hline & 55318 & 27005 & 77048 & 85476 & 79251 & & 1651848 & 1757680 & 62138 & 2021140 & 1976066 & 29273 & 1753525 & & & & & & & \\
\hline 3 & 052227 & 1885855 & 67298 & 1754219 & 1562350 & 368001 & 1536593 & 1635235 & 1732481 & 1880405 & 1838494 & 1701927 & 1631404 & 1628302 & 1663323 & 1670040 & 1654450 & 1627218 & 1684978 & 160032 \\
\hline 4 & 35900 & 79613 & 63047 & 1562360 & 1391716 & 1218672 & 1368851 & 1456486 & 542985 & 1674518 & 1637231 & $15157 \mathrm{7}$ & 1452992 & 1450167 & 1481419 & 1487320 & 1473414 & 1449214 & LOS & 1425196 \\
\hline 7 & 69399 & 1757989 & 740644 & 1635235 & 1456486 & 1275499 & 1432921 & 1524685 & 1615113 & 1752552 & 1713957 & 1585678 & 1521046 & 1517952 & 1550643 & 1556344 & 1542259 & $151688 \mathrm{~s}$ & 1570892 & 1491873 \\
\hline 8 & 80476 & 52450 & 44135 & 1732481 & 1542985 & 1351100 & 1517772 & 1615113 & 1711133 & 1857197 & 1815857 & 1680968 & 1611306 & 1608122 & 1642739 & 1649447 & 1633997 & 1607097 & 1664201 & 158052 \\
\hline 9 & & & & 1 & 1674 & & & & & & 1970 & & & & & 90273 & & & & 17155 \\
\hline 10 & 01773 & 76441 & 56977 & 1838494 & 1637281 & 1433658 & 1610579 & 1713957 & 1815857 & 1970342 & 1927204 & 1783905 & 1709996 & 1706613 & 1743313 & 1750570 & 1734114 & 1705542 & 1766126 & 167743 \\
\hline 11 & 45599 & 1829624 & 1811601 & 1701927 & 1515778 & 1327301 & 1491043 & 1586678 & 1680968 & 1824477 & 1783905 & 1651377 & 1582568 & 1579804 & 1613808 & 1620403 & 1605235 & 1578810 & 1634508 & 155271 \\
\hline 13 & & 1717659 & 1700764 & 1597922 & 1424009 & 1247219 & 1400471 & 1459966 & 1578026 & 1712634 & 1675081 & 1550436 & 1486363 & 1483576 & 1515530 & 1522131 & 1507706 & 1482854 & 1535130 & 145865 \\
\hline 14 & 36222 & 1727755 & 1711168 & 1607374 & 1432806 & 1254195 & 1407675 & 1497432 & 1586620 & 1722011 & 1683002 & 1558373 & 1493433 & 1491883 & 1524031 & 1529456 & 1516354 & 1490845 & & 1465914 \\
\hline 15 & 1820826 & 1714309 & 1698239 & 1594788 & 1420747 & 1243271 & 1395824 & 1484143 & 1573278 & 1708770 & 1668197 & 1544929 & 1481048 & 1482915 & 1512321 & 11515351 & 1503992 & 1478739 & 1530177 & 145389: \\
\hline 16 & 780564 & 1677276 & 1661245 & 1560075 & 1359913 & 1216136 & 1365015 & 1451052 & 1538001 & 1670605 & 1631178 & 1510230 & 1448077 & 1449599 & 1479264 & 41492242 & 1470480 & 1446291 & 1496232 & 142217 \\
\hline 17 & 34959 & 1634688 & 1618532 & 1519958 & 1355139 & 1185473 & 1329820 & 1413311 & 1497698 & 1626761 & 1588740 & 1470941 & 1410334 & 1411134 & 1441277 & 1444086 & 1432257 & 1409263 & 1457198 & 1385707 \\
\hline 18 & 783529 & 1680371 & 1663198 & 1562039 & 1393533 & 1219718 & 1367846 & & 1535003 & & 1633263 & & & 1450985 & & & 1471958 & 1448853 & 1498271 & 142506 \\
\hline 19 & 678016 & 1530716 & 1564322 & 1468714 & 1310316 & 1147907 & 1288691 & 1368493 & 1447569 & 1573010 & 1536545 & 1423050 & 1366431 & 1365814 & 1394467 & 1396511 & 1384831 & 1362703 & 1410399 & 13412 \\
\hline
\end{tabular}

Gambar 7. Tabel Transformasi linear berwarna Red

Langkah 5 : Gambar RGB yang dinormalisasi mundur ke kisaran $[0,255]$

$$
\begin{aligned}
& \mathrm{R}^{\prime}=255 \times \mathrm{R}^{\prime} \mathrm{n} \\
& \mathrm{G}^{\prime}=255 \times \mathrm{G}^{\prime} \mathrm{n} \\
& \mathrm{B}^{\prime}=255 \times \mathrm{B}^{\prime} \mathrm{n}
\end{aligned}
$$

Adapun cara untuk menghitung nilai RGB yang dinormalisasi pada pixel Red bisa dilihat dalam pengerjaan dibawah ini. 
$(0,0)=255 \times 2292303=584537163$

$(0,1)=255 \times 2155712=549706644$

$(0,2)=255 \times 2134472=544290382$

$(0,3)=255 \times 2005227=511332893$

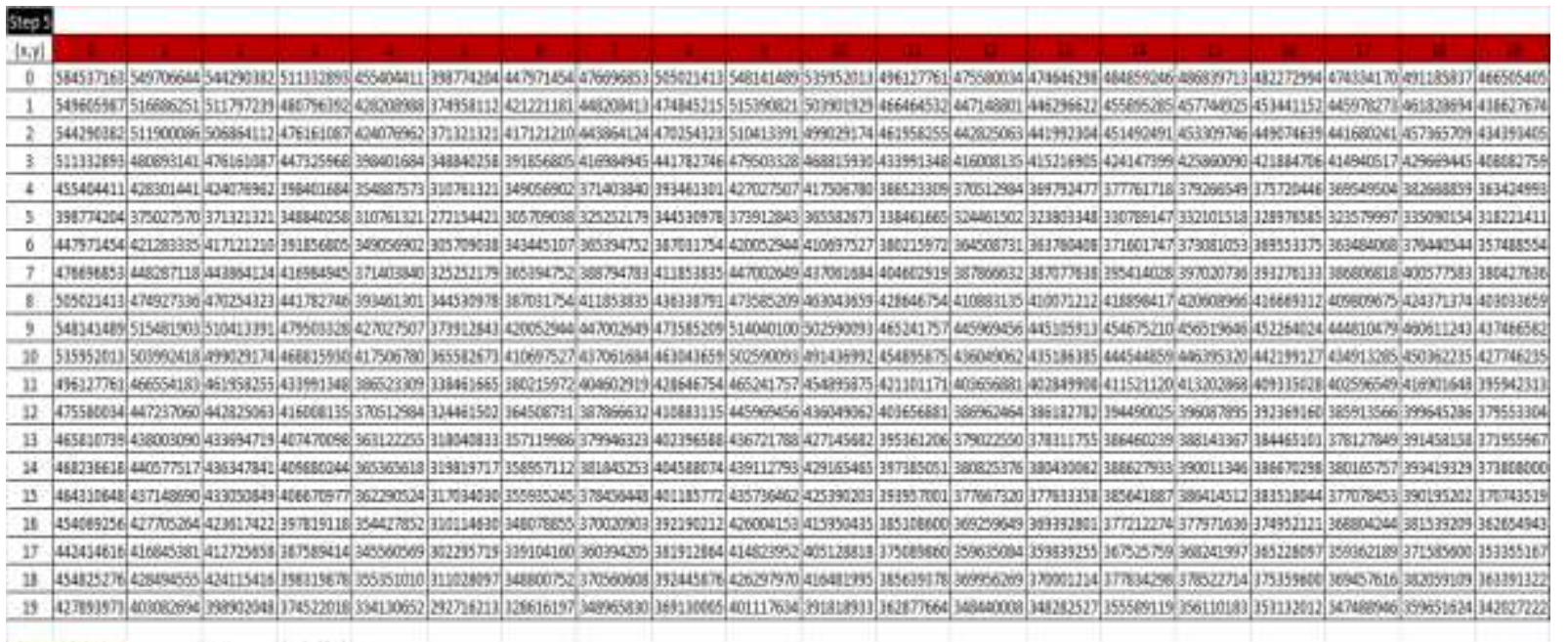

Gambar 8. Tabel RGB yang dinormalisasi berwarna Red

Langkah 6 : Output akhir gambar RGB dapat dihitung sebagai

$$
\begin{aligned}
& \mathrm{R} 1=\frac{\mathrm{R}^{\prime}-\mathrm{R}^{\prime} \min }{\mathrm{R}^{\prime} \max -\mathrm{R}^{\prime} \min } \\
& \mathrm{G} 1=\frac{\mathrm{G}^{\prime}-\mathrm{G}^{\prime} \min }{\mathrm{G}^{\prime} \mathrm{max}-\mathrm{R}^{\prime} \min } \\
& \mathrm{B} 1=\frac{\mathrm{B}^{\prime}-\mathrm{B}^{\prime} \min }{\mathrm{B}^{\prime} \max -\mathrm{B}^{\prime} \min }
\end{aligned}
$$

Pada langkah terakhir tahap pertama yang dilakukan terlebih dahulu ialah mencari nilai maximum dan nilai minimumnya, setelah nilai maximum dan nilai minimum sudah didapat selanjutnya hasil dari pengurangan nilai $\mathrm{R}$ dengan nilai minimum dibagi dengan hasil pengurangan nilai maximum dan minimum. Untuk lebih jelasnya bisa dilihat pada pengerjaan di bawah ini.

Nilai $\max =584537163$

\begin{tabular}{|c|c|c|c|c|c|c|c|c|c|c|c|c|c|c|c|c|c|c|c|c|}
\hline tep 6 & & & & & & & & & & & & & & & & & & & & \\
\hline$(x, y)$ & 0 & 1 & 2 & 3 & 4 & 5 & 6 & 7 & 8 & 9 & 10 & 11 & 12 & 13 & 14 & 15 & 16 & 17 & 18 & 19 \\
\hline o & 1 & 1 & 1 & 1 & 1 & o & 1 & 1 & 1 & 1 & 1 & 1 & 1 & 1 & 1 & 1 & 1 & 1 & 1 & 1 \\
\hline 1 & 1 & 1 & 1 & 1 & 0 & 0 & 0 & 1 & 1 & 1 & 1 & 1 & 1 & 1 & 1 & 1 & 1 & 1 & 1 & 1 \\
\hline 2 & 1 & 1 & 1 & 1 & 0 & 0 & 0 & 1 & 1 & 1 & 1 & 1 & 1 & 1 & 1 & 1 & 1 & 1 & 1 & 1 \\
\hline 3 & 1 & 1 & 1 & 1 & 0 & o & 0 & o & 1 & 1 & 1 & 1 & 0 & 0 & 0 & 0 & 0 & 0 & 1 & 0 \\
\hline 4 & 1 & 0 & 0 & 0 & 0 & 0 & 0 & 0 & 0 & 0 & 0 & 0 & 0 & 0 & 0 & 0 & 0 & 0 & 0 & 0 \\
\hline 5 & 0 & 0 & 0 & 0 & 0 & 0 & 0 & 0 & 0 & 0 & 0 & 0 & 0 & 0 & 0 & 0 & 0 & 0 & 0 & 0 \\
\hline 6 & 1 & 0 & 0 & o & o & o & o & 0 & 0 & o & 0 & o & 0 & 0 & 0 & o & o & o & 0 & o \\
\hline 7 & 1 & 1 & 1 & 0 & 0 & 0 & 0 & 0 & 0 & 1 & 1 & 0 & 0 & 0 & 0 & 0 & 0 & 0 & 0 & 0 \\
\hline 8 & 1 & 1 & 1 & 1 & 0 & 0 & 0 & 0 & 1 & 1 & 1 & 1 & 0 & 0 & 0 & 0 & 0 & 0 & 0 & 0 \\
\hline 9 & 1 & 1 & 1 & 1 & 0 & 0 & o & 1 & 1 & 1 & 1 & 1 & 1 & 1 & 1 & 1 & 1 & 1 & 1 & 1 \\
\hline 10 & 1 & 1 & 1 & 1 & 0 & 0 & 0 & 1 & 1 & 1 & 1 & 1 & 1 & 1 & 1 & 1 & 1 & 1 & 1 & 0 \\
\hline 11 & 1 & 1 & 1 & 1 & 0 & 0 & 0 & 0 & 1 & 1 & 1 & 0 & 0 & 0 & 0 & 0 & 0 & 0 & 0 & 0 \\
\hline 12 & 1 & 1 & 1 & 0 & 0 & 0 & 0 & o & 0 & 1 & 1 & o & 0 & 0 & 0 & o & 0 & o & 0 & o \\
\hline 13 & 1 & 1 & 1 & 0 & 0 & 0 & 0 & 0 & 0 & 1 & 0 & 0 & 0 & 0 & 0 & 0 & 0 & 0 & 0 & 0 \\
\hline 14 & 1 & 1 & 1 & 0 & 0 & 0 & 0 & 0 & 0 & 1 & 1 & 0 & 0 & 0 & 0 & 0 & 0 & 0 & 0 & 0 \\
\hline 15 & 1 & 1 & 1 & 0 & o & o & 0 & o & 0 & 1 & 0 & o & 0 & o & 0 & o & o & 0 & 0 & o \\
\hline 16 & 1 & 0 & 0 & 0 & 0 & 0 & 0 & 0 & 0 & 0 & 0 & 0 & 0 & 0 & 0 & 0 & 0 & 0 & 0 & 0 \\
\hline 17 & 1 & 0 & 0 & 0 & 0 & 0 & 0 & 0 & 0 & 0 & 0 & 0 & 0 & 0 & 0 & 0 & 0 & 0 & 0 & 0 \\
\hline 18 & 1 & 1 & o & 0 & 0 & o & 0 & 0 & 0 & 0 & 0 & o & 0 & 0 & 0 & o & 0 & o & 0 & 0 \\
\hline 19 & 0 & 0 & o & 0 & 0 & 0 & 0 & 0 & 0 & 0 & 0 & 0 & 0 & 0 & 0 & 0 & 0 & 0 & 0 & 0 \\
\hline
\end{tabular}

Nilai $\min =272154421$

$(0,0)=\frac{584537163-272154421=1}{584537163-272154421}$

Gambar 9. Tabel Hasil Akhir

Setelah didapatkan nilai hasil akhir selanjutnya nilai tersebut digabungkan dengan nilai matriks warna Red untuk lebih jelasnya dapat dilihat pada pengerjaan di bawah ini. 
$(0,0)=1+47=48$

$(0,1)=1+35=36$

$(0,2)=1+39=40$

$(0,3)=1+65=66$

\begin{tabular}{|c|c|c|c|c|c|c|c|c|c|c|c|c|c|c|c|c|c|c|c|c|}
\hline$(x, y)$ & 0 & 1 & 2 & 3 & 4 & 5 & 6 & 7 & 8 & 9 & 10 & 11 & 12 & 13 & 14 & 15 & 16 & 17 & 18 & 19 \\
\hline 0 & 48 & 36 & 40 & 66 & 66 & 59 & 59 & 55 & 67 & 77 & 78 & 92 & 92 & 91 & 96 & 86 & 79 & 99 & 77 & 67 \\
\hline 1 & 28 & 51 & 58 & 52 & 43 & 32 & 35 & 46 & 62 & 54 & 73 & 97 & 95 & 88 & 104 & 106 & 81 & 79 & 86 & 71 \\
\hline 2 & 29 & 57 & 69 & 48 & 40 & 37 & 40 & 45 & 60 & 58 & 58 & 83 & 82 & 96 & 94 & 96 & 88 & 78 & 93 & 77 \\
\hline 3 & 33 & 51 & 60 & 45 & 44 & 43 & 39 & 41 & 46 & 51 & 57 & 65 & 70 & 82 & 88 & 95 & 76 & 86 & 86 & 85 \\
\hline 4 & 29 & 35 & 27 & 25 & 37 & 33 & 19 & 37 & 44 & 29 & 39 & 54 & 65 & 81 & 96 & 97 & 81 & 96 & 94 & 90 \\
\hline 5 & 23 & 16 & 9 & 18 & 27 & 32 & 34 & 49 & 40 & 41 & 41 & 44 & 46 & 70 & 79 & 69 & 76 & 89 & 85 & 85 \\
\hline 6 & 20 & 15 & 20 & 23 & 20 & 38 & 62 & 62 & 63 & 68 & 60 & 48 & 63 & 76 & 77 & 54 & 75 & 85 & 75 & 87 \\
\hline 7 & 34 & 35 & 32 & 21 & 28 & 52 & 69 & 50 & 55 & 56 & 54 & 74 & 64 & 68 & 76 & 74 & 76 & 73 & 82 & 89 \\
\hline 8 & 33 & 39 & 54 & 40 & 51 & 56 & 65 & 54 & 52 & 50 & 60 & 56 & 66 & 85 & 79 & 79 & 86 & 72 & 84 & 70 \\
\hline 9 & 32 & 40 & 69 & 63 & 51 & 62 & 59 & 68 & 76 & 72 & 74 & 61 & 72 & 79 & 73 & 72 & 83 & 79 & 75 & 79 \\
\hline 10 & 34 & 27 & 57 & 77 & 66 & 63 & 49 & 62 & 77 & 65 & 65 & 61 & 75 & 75 & 74 & 67 & 74 & 82 & 72 & 83 \\
\hline 11 & 38 & 34 & 36 & 46 & 54 & 55 & 60 & 55 & 62 & 52 & 61 & 65 & 66 & 62 & 78 & 80 & 76 & 77 & 79 & 72 \\
\hline 12 & 31 & 39 & 28 & 26 & 42 & 42 & 64 & 70 & 70 & 70 & 68 & 64 & 54 & 47 & 61 & 70 & 71 & 81 & 77 & 79 \\
\hline 13 & 36 & 48 & 43 & 43 & 44 & 33 & 35 & 57 & 63 & 75 & 64 & 57 & 62 & 61 & 52 & 60 & 72 & 76 & 85 & 78 \\
\hline 14 & 26 & 40 & 43 & 45 & 45 & 47 & 36 & 47 & 62 & 69 & 70 & 64 & 70 & 68 & 60 & 58 & 79 & 76 & 80 & 91 \\
\hline 15 & 30 & 33 & 38 & 51 & 57 & 54 & 37 & 38 & 58 & 43 & 54 & 61 & 72 & 76 & 79 & 65 & 65 & 73 & 84 & 105 \\
\hline 16 & 44 & 39 & 45 & 53 & 68 & 52 & 27 & 43 & 55 & 47 & 57 & 74 & 68 & 66 & 53 & 59 & 63 & 77 & 79 & 96 \\
\hline 17 & 43 & 35 & 44 & 45 & 55 & 57 & 36 & 41 & 54 & 51 & 59 & 62 & 52 & 55 & 57 & 70 & 79 & 79 & 77 & 96 \\
\hline 18 & 36 & 43 & 45 & 35 & 34 & 58 & 62 & 64 & 63 & 60 & 65 & 60 & 52 & 56 & 61 & 72 & 83 & 74 & 77 & 89 \\
\hline 19 & 39 & 38 & 38 & 43 & 43 & 43 & 53 & 62 & 58 & 53 & 55 & 50 & 49 & 53 & 61 & 74 & 75 & 73 & 77 & 80 \\
\hline
\end{tabular}

Gambar 10. Tabel Hasli Penggabungan Warna Red

\section{IMPLEMENTASI}

Hasil merupakan suatu proses dari penyelesaian suatu masalah yang mana masalah ini adalah untuk perbaikan citra maps. Tampilan pengujian merupakan proses yang bertujuan untuk memastikan apakah semua fungsi sistem bekerja dengan baik dan mencari kesalahan yang mungkin terjadi pada sistem. Pada pengujian perbaikan kualitas citra maps menggunakan metode CLAHE juga dilakukan terhadap citra satelit atau citra permukaan yang diambil dari atas atau ketinggian menggunakan drone, Adapun hasil pengujian dari dari beberapa citra maps yang telah di perbaiki yaitu

Tabel 4.1 Pengujian

\begin{tabular}{l|l}
\hline No & Gambar Input \\
\hline 1 & \\
& \\
& \\
& \\
& \\
&
\end{tabular}

\section{Gambar Output}

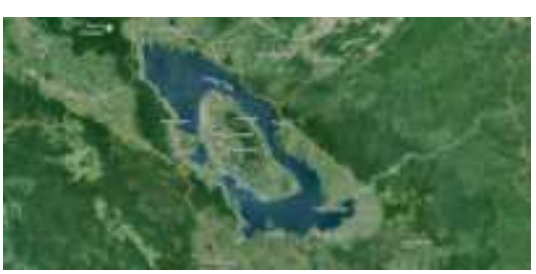

2
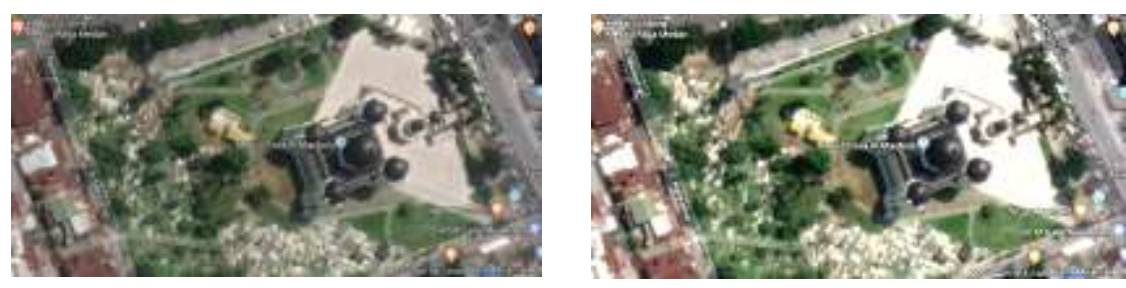

3
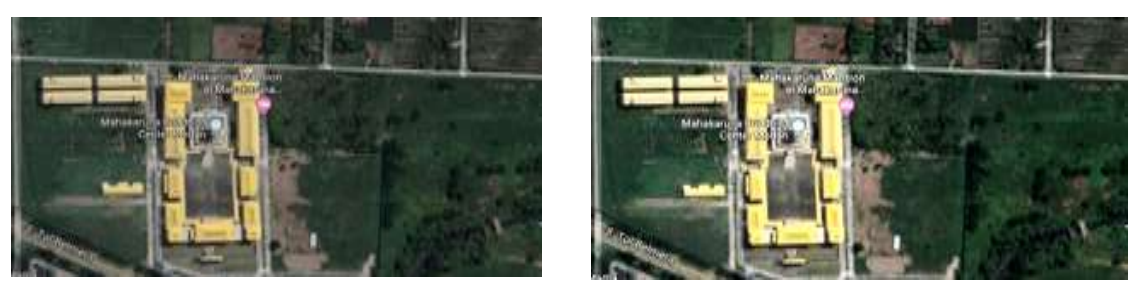
4
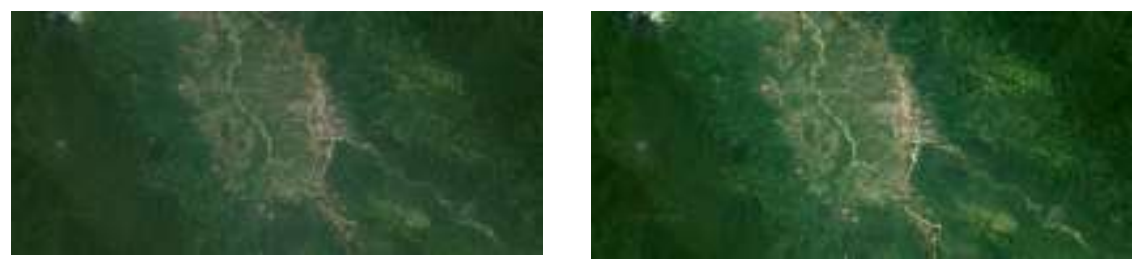

5
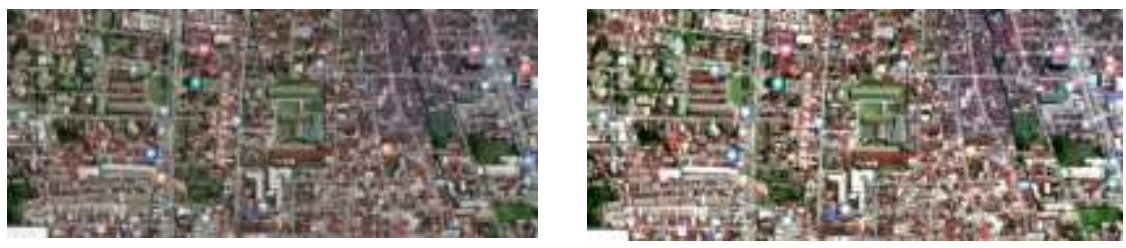

\section{KESIMPULAN}

1. Teknik Perbaikan kualitas citra digital dengan meningkatkan intensitas citra digital yang unsur pencahayaan kurang dimiliki pada saat pengambilan citra digital, piksel-piksel citra berwarna tersebut yang terdiri dari RGB dapat diolah menggunakan cara peningkatan kontras.

2. Penerapan metode CLAHE berbasis ruang YIQ dengan Rayleigh. Algoritma CLAHE dapat diterapkan sebagai solusi dalam perbaikan kualitas citra untuk memudahkan proses perbaikan kualitas atau peningkatan kontras agar lebih mudah dan cepat.

\section{REFERENCES}

[1] R. Munir, "Pengolahan Citra," 2004.

[2] Purnama \& Hariadi Andono, "UNDERWATER IMAGE ENHANCEMENT USING ADAPTIVE FILTERING FOR ENHANCED SIFT-BASED IMAGE MATCHING," 2013.

[3] Darma Putra, Pengolahan Citra Digital, Westriningsih, Ed. Yogyakarta: ANDI, 2010.

[4] S.Si.,M.Kom, Edy Mulyanto, Dr. Vincent Suhartono, Oky Dwi Nurhayati, Wijanarto, M.Kom T.Sutoyo, Teori Pengolahan Citra Digital, Benedicta Rini W, Ed. Semarang:UDINUS, Yogyakarta:ANDI, 2009.

[5] EP Amburnus, JD Austin, dkk SM Pizer, Adaptive Histogram Equalization and Variasinya. Visi Komputer, Grafik, dan Pemrosesan Gambar 39., (1987) 355-368.

[6] Eddy Prahasta, MENGELOLA PETA DIGITAL. Informatika Bandung, Mei 2013.

[7] AS Rosa dan M.Shalahuddin, Rekayasa Perangkat lunak., 2016. 